\title{
ENTRE MEMÓRIA E HISTÓRIA: A NARRATIVA POÉTICA DO JOVEM GILBERTO FREYRE
}

\author{
ENTRE MEMORIA E HISTORIA: LA NARRATIVA POÉTICA DEL JOVEN GILBERTO \\ FREYRE
}

\author{
BETWEEN MEMORY AND HISTORY: THE POETIC NARRATIVE OF THE YOUNG \\ GILBERTO FREYRE
}

\section{ENTRE MÉMOIRE ET HISTOIRE : LA NARRATION POÉTIQUE DU JEUNE GILBERTO FREYRE}

\author{
介于回忆录与历史之间: 吉尔贝托 . 福来利 \\ (GILBERTO FREYRE)年青时代的具有诗歌特征的文体
}

DOI: $10.5533 / 1984-2503-20135307$

\section{Claudio Marcio Coelho ${ }^{1}$}

\section{RESUMO}

Este artigo discute algumas interfaces entre memória e história, a partir da contribuição de autores contemporâneos, a saber, Pierre Nora, Michael Pollak, Jacques Le Goff, Roger Chartier, entre outros. Num segundo momento, investigamos como o cientista social Gilberto Freyre construiu sua narrativa histórica em diálogo com as interfaces discutidas por esses autores. Essa investigação está orientada pela hipótese de que Freyre realizou seu projeto intelectual (entre 1922 e 1926) percorrendo as fronteiras da memória e da história. Demonstramos como nosso autor realizou uma "relação simbiótica" entre história, memória e tempo poético a partir da conciliação de áreas como ciência, literatura e cultura popular.

Palavras-chave: História, Memória, Narrativa Histórica, Brasil, Gilberto Freyre.

\footnotetext{
${ }^{1}$ Doutorando em História pelo Programa de Pós-Graduação em História Social das Relações Políticas da Universidade Federal do Espírito Santo (UFES). Membro da Diretoria Executiva do Núcleo de Estudos e Pesquisas Indiciárias (NEI), vinculado ao Departamento de Ciências Sociais da UFES. Desenvolve atividades de estudo, pesquisa e extensão no NEI, onde coordena o Laboratório de Estudos sobre Teorias da Complexidade (LETEC), a Linha de Pesquisa Ciência, Arte \& Cultura e o Grupo de Estudos em Pensamento Social Brasileiro. Desenvolve estudos e docência nas seguintes áreas: Antropologia Cultural e Filosófica, Sociologia, História Cultural, Método Indiciário e Teorias da Complexidade.

E-mail: claudiomarciocoelho@gmail.com
} 


\section{RESUMEN}

Este artículo discute algunas interfaces entre memoria e historia, a partir de la contribución de autores contemporáneos, como Pierre Nora, Michael Pollak, Jacques Le Goff, Roger Chartier, entre otros. En un según momento, investigamos como el científico social Gilberto Freyre ha construido su narrativa histórica en diálogo con las interfaces discutidas por estos autores. Esta investigación es orientada por la hipótesis de que Freyre ha realizado su proyecto intelectual (entre 1922 y 1926) recurriendo las fronteras de la memoria y de la historia. Objetivamos demostrar como nuestro autor ha realizado una "relación simbiótica" entre historia, memoria y tiempo poético a partir de la conciliación de áreas como ciencia, literatura y cultura popular.

Palabras clave: Historia, Memoria, Narrativa Histórica, Brasil, Gilberto Freyre.

\section{ABSTRACT}

This article discusses several interfaces between memory and history, based on the contribution of the following contemporary authors: Pierre Nora, Michael Pollak, Jacques Le Goff and Roger Chartier, among others. It then investigates how social scientist Gilberto Freyre constructed his historical narrative in a dialogue with the interfaces discussed by these authors. This investigation is oriented by the hypothesis that Freyre undertook his intellectual project (between 1922 and 1926) tracing the borders of memory and of history. We demonstrate how the author proposed a "symbiotic relationship" between history, memory and poetic time based on the conciliation of fields such as science, literature and popular culture.

Key words: History, Memory, Historical Narrative, Brazil, Gilberto Freyre.

\section{RÉSUMÉ}

Cet article analyse certaines interfaces entre mémoire et histoire à partir de la contribution d'auteurs contemporains comme Pierre Nora, Michael Pollak, Jacques Le Goff et Roger Chartier, entre autres. Dans un deuxième temps, nous étudierons la manière dont le scientifique social a construit son récit historique en dialogue avec les interfaces débattues par ces auteurs. Cette recherche se base sur l'hypothèse selon laquelle G. Freyre aurait mis en œuvre son projet intellectuel (entre 1922 et 1926) aux frontières de la mémoire et de l'histoire. Nous montrerons comment notre auteur a mis en place une « relation 
symbiotique » entre histoire, mémoire et temps poétique à partir de la conciliation de domaines comme la science, la littérature et la culture populaire.

Mots-clés: Histoire, Mémoire, Récit historique, Brésil, Gilberto Freyre.

\section{摘要}

本论文首先讨论回忆录与历史两种文体的交叉问题, 理论依据是当代法国学者的观点一

诺拉(Pierre Nora), 波拉克(Michael Pollak), 雷高福(Jacques Le Goff), 夏提诶(Roger Chartier)。在理论基础上分析研究巴西著名社会学家吉尔贝托 ·福来利(Gilberto

Freyre)的史学著作的文体的交叉特色。本文作者认为, 吉尔贝托 . 福来利在 1922 年到 1926 年期间的学术著作的文体介于回忆录与历史论文之间，“共生”于历史，回忆录，诗韵，穿插 并调和了科学, 文学和民众文化。

关键字：历史，回忆录，历史叙述，巴西，吉尔贝托 ·福来利(Gilberto Freyre)

\section{Introdução}

O tempo poetiza as pessoas e as coisas.

(Gilberto Freyre, 1921)

O estudo da memória conduz-nos inevitavelmente para a investigação e a discussão de temas complementares como passado, lembranças, esquecimentos, história. Esse estudo também revela-nos que a pesquisa acerca da memória é um trabalho de constante reconstrução. O mesmo também se aplica ao trabalho do historiador.

Apesar da crise paradigmática dos modelos centrados no racionalismo cartesiano e no positivismo científico, ainda estamos apegados a ilusão de que o passado pode ser reconstituído e recuperado em sua integralidade. Mas o que resta ao historiador é a possibilidade de uma "reconstrução ideal" do passado, pois "todo o trabalho histórico parte da idealização de uma possibilidade de compreensão". ${ }^{2}$ Como demonstrou HansGeorg Gadamer (2002), o historiador só pode realizar a hermenêutica do passado pelo reconhecimento de que o objetivismo é uma ilusão, e de que todo esforço de

\footnotetext{
${ }^{2}$ Santos, Afonso C.M. dos (1998). Memória e história das ciências. Transcrição da palestra apresentada no MAST COLLOQUIA, em 05 de maio, Rio de Janeiro, p.13.
} 
compreensão da realidade está inevitavelmente atravessado pela incompletude e pela incerteza. $^{3}$ Muitos ainda estão apegados a conceitos/teorias estanques e insulares, apesar dos incomensuráveis avanços provocados pela inovação epistemológica introduzida na física quântica com o "princípio da indeterminação" de Werner Heisenberg (1927), na filosofia com o "conhecimento aproximado" de Gaston Bachelard (1928) e o "pensamento complexo" de Edgar Morin (1990), e na história com a "perspectiva indiciária" de Carlo Ginzburg (1989). ${ }^{4}$

Estamos convencidos de que o trabalho histórico não é o contato direto com a experiência humana do passado, mas o trato com vestígios, fragmentos, indícios que nos apresentam apenas um espectro dessa experiência. Por isso, o estudo histórico necessita de um exercício crítico permanente, pois o que torna o passado inteligível e compreensível é a tradução do historiador. Ademais, o historiador pode descortinar as relações de complementaridade entre memória e história, enriquecendo seu esforço de (re)construção imaginativa do passado.

Partindo dessas premissas, identificaremos alguns autores e trabalhos contemporâneos que dissertaram sobre memória e história. Inicialmente, apresentaremos um panorama geral acerca do tema, discutindo suas interfaces. Depois, investigaremos como o jovem Gilberto Freyre construiu sua narrativa histórica a partir dessas interfaces. Essa investigação será orientada pela hipótese de que Freyre realizou seu projeto intelectual percorrendo as fronteiras da memória e da história. Evitando uma leitura sedimentada em uma única possibilidade, o jovem intelectual pernambucano preferiu transitar entre a memória e a história para construir um painel histórico vívido, poético e racional do passado brasileiro.

\section{Acerca de memória e história: absorvendo alguns autores e obras}

Pierre Nora coordenou um trabalho clássico e modelar para a historiografia francesa e mundial, e que tem influenciado pensadores no mundo inteiro. Uma obra coletiva que chamou de Les lieux de memorie ${ }^{5}$, composta por sete volumes publicados entre 1984 e 1994. No Brasil, a Revista Projeto História 10, da PUC/SP, publicou a

\footnotetext{
${ }^{3}$ Ver: Gadamer, Hans-Georg (2002). Verdade e método II, Petrópolis, RJ: Vozes.

${ }^{4}$ Ver: Bachelard, Gaston (2004). Ensaio sobre o conhecimento aproximado, Rio de Janeiro: Contraponto; Morin, Edgar (2005). O método 3: o conhecimento do conhecimento, Porto Alegre: Sulina; Ginzburg, Carlo (1989). Mitos, emblemas, sinais: morfologia e história, São Paulo: Cia das letras.

${ }^{5}$ Os lugares de memória.
} 
tradução de um texto que apresenta a obra. Um texto intitulado Entre memória e história: a problemática dos lugares, no qual Nora (1993) demarca diferenças esclarecedoras entre memória e história, a começar pelo reconhecimento de que não são conceitos sinônimos. Pelo contrário, hoje somos obrigados a revelar sua oposição permanente.

Para Nora, a memória é a "vida, sempre carregada por grupos", por isso, está "aberta à dialética da lembrança e do esquecimento", mas também é "inconsciente de suas deformações sucessivas", "vulnerável a todos os usos e manipulações", susceptível a transformações ou reedições no tempo e no espaço. Por outro lado, a "história é a reconstrução problemática e incompleta do que não existe mais", pois consiste na representação do passado, enquanto a memória é um fenômeno atual e um elo "vivido no eterno presente". Também é "afetiva e mágica". E se "alimenta de lembranças vagas, telescópicas, globais, flutuantes, particulares ou simbólicas". Mas essas lembranças são sensíveis "a todas as transferências e cenas", censuras ou projeções. Assim, a memória aciona a lembrança do sagrado, une os grupos sociais e se enraíza no concreto, no símbolo, no gesto, na imagem e no espaço. A história, por sua vez, é uma operação intelectual e laicizante, que demanda análise e discurso crítico. Sua vocação volta-se para o universal, pois está ligada "às continuidades temporais, às evoluções e às relações das coisas. A memória é um absoluto e a história só conhece o relativo". 6

Sabemos que a força dos símbolos é imbatível, por isso, a memória constitui objeto privilegiado na disputa pelo poder. Assim, manipulada em sua função política, silenciada ou esquecida em sua representação do passado, a memória coletiva torna-se instrumento e objeto de poder. Como afirmou Jacques Le Goff, "os esquecimentos e os silêncios da história são reveladores desses mecanismos de manipulação da memória coletiva". ${ }^{7}$

A crítica de Le Goff é legítima, e indica-nos as consequências decorrentes daquilo que Michael PollaK chamou de "enquadramento da memória". Em Memória, esquecimento, silêncio, Pollak (1989) lembra a contribuição de Maurice Halbwachs e Pierre Nora para o estudo da memória. Destaca a importância que atribuíram ao estudo dos monumentos, do patrimônio arquitetônico, das paisagens, das datas e personagens históricas, das tradições e costumes, regras de interação social, folclore, música e tradições culinárias. Assim, Halbwachs acentuou as funções positivas desempenhadas

\footnotetext{
${ }^{6}$ Nora, Pierre (1993). "Entre memória e história: a problemática dos lugares”. In Projeto História, n.10, p. 9.

${ }^{7}$ Le Goff, Jacques (1990). História e memória, Campinas: Ed. UNICAMP, p.26.
} 
pela memória no reforço da coesão social. Um reforço que se manifesta pela adesão afetiva dos indivíduos ao grupo, que chamou de "comunidade afetiva".

Sabemos, por teoria e por experiência, que o controle das metáforas, dos símbolos e das tradições, torna-se alvo privilegiado na disputa pelo poder. Por isso, consideramos as lutas de representações como processos tão importantes quanto às lutas econômicas, como demonstrou Roger Chartier em $A$ história cultural: entre práticas e representações (2002).

Nessa obra, Chartier discute as limitações advindas dos "falsos discursos" que professam a impossibilidade de diálogo e de aproximação entre estudos voltados para a "objetividade das estruturas" (terreno da história alicerçada na quantificação, no rigor teórico-empírico) e para a "subjetividade das representações" (uma história considerada menor e reprodutora de discursos distanciados do real). Segundo Chartier, a superação da dicotomia decorrente dessas limitações revelará "os esquemas geradores das classificações e das percepções" como "verdadeiras instituições sociais, incorporando sob a forma de categorias mentais e de representações coletivas, as demarcações da própria organização social". 9

Se considerarmos as representações coletivas como elementos que estruturam o imaginário social, somos obrigados a reconhecer que mitos, crenças e tradições, representam as formas como uma sociedade imagina/pensa/sente suas relações sociais. Essas representações constituem o que Nora chamou de "lugares de memória". Lugares no sentido simbólico. Existem também lugares no sentido material e funcional. Mas, um depósito de arquivos, um testamento, os documentos oficiais e extraoficiais, os manuais de aula, por exemplo, só são lugares de memória se a "imaginação" os investe de uma aura simbólica e/ou se forem objetos de um ritual. É preciso ter "vontade de memória", pois na falta dessa intenção ${ }^{10}$, os lugares de memória serão apenas "lugares de história". 11

Assim, o estudo dessas representações revelará as "imagens mentais claras" ou os "materiais de ideias" - segundo Lucien Febvre - do contexto estudado. Chartier considera necessário tomar o conceito de representação num sentido particular e historicamente

\footnotetext{
${ }^{8}$ Ver: Pollak, Michael (1989). "Memória, esquecimento, silêncio”. In Estudos Históricos, v.2, n.3, p.3-15.

${ }^{9}$ Chartier, Roger (1990). A história cultural: entre práticas e representações, Rio de Janeiro/Lisboa: Bernard Brasil/Difel, p.18.

${ }^{10}$ Mitos, símbolos, tradições, crenças e rituais estão sempre atravessados por intencionalidades, desejos, afetos e fantasias humanas, "demasiadamente humanas", como diria Friedrich Nietzsche.

${ }^{11}$ Nora, P. (1993). Op. Cit., p.22.
} 
determinado, considerando a representação como "coisa ausente" ou como "exibição de uma presença, como apresentação pública de algo ou de alguém". A representação coletiva constitui um instrumento de conhecimento mediato, onde o objeto ausente é substituído por uma "imagem" capaz de reconstituí-lo em memória ou de figurá-lo como ele é. ${ }^{12}$

Nesse sentido, a obra História e memória, de Jacques Le Goff (1990), auxilia-nos na discussão de nosso tema. Le Goff considera o "estudo da memória social como um dos meios fundamentais de abordar os problemas do tempo e da história". ${ }^{13}$ Também valoriza as proposições de H.L.Bergson (1896) em Matière et mémoire sobre a centralidade da noção de imagem "na encruzilhada da memória e da percepção"14, realçando a existência de uma memória profunda, pessoal, pura, e de seus laços com o espírito humano (alma, mente, psiché). A teoria de Bergson teve grande influência sobre a literatura de Marcel Proust, e marca o ciclo narrativo do autor em $A$ la recherche du temps perdu (1913-27). Esta influência fez nascer uma nova memória romanesca, gerando a cadeia/relação mito-história-romance.

Considerando a contribuição desses autores, poderemos eleger algumas categorias problematizadas nos trabalhos supracitados para a análise das interfaces entre memória e história no pensamento do jovem Gilberto Freyre: a ideia de memória romanesca (Le Goff); de comunidade afetiva (Halbwachs); de memória coletiva (Chartier); os lugares de memória (Nora), por exemplo.

\section{História, memória e tempo poético: uma relação simbiótica em Gilberto Freyre}

Desde jovem, o autor tende a ser, criar o seu próprio ritmo ou seu próprio estilo, tanto sociológico como, até, filosófico, de ser ou, como diria o espanhol, de "estar sendo" quanto tem sido. Daí ser, talvez, menos sociólogo que antropólogo. Daí ser, também - ou procurar ser - historiador social: um historiador social que junte "simbioticamente" a história social à sociologia. Daí, ainda, ser dos que não hesitam em procurar abrir comunicações da sociologia com a literatura e com a filosofia, admitindo aquela validade do "modo poético de conhecimento" como complementar, nuns tantos casos, do "modo científico"... 15

(Gilberto Freyre, 1968)

\footnotetext{
${ }^{12}$ Chartier, R. (1990). Op. Cit., p. 20.

${ }^{13}$ Le Goff, J. (1990). Op. Cit., p. 426.

14 lbidem, p.471.

${ }^{15}$ Freyre, Gilberto (1968). Como e porque sou e não sou sociólogo, Brasília: Ed. UNB, p.25.
} 
O Brasil do início do século XX estava sob o domínio intelectual da França. Lia-se preferencialmente Anatole France, Zola, Julio Verne, Maupassant, Flaubert e Renan. Os filhos das famílias abastadas estudavam tudo quanto representava a cultura francesa: a língua, a literatura, as artes. O jovem Gilberto Freyre não fugiu a influência desse espírito da Belle époque. Também admirava a literatura dos irmãos Goncourt desde a adolescência. As anotações de seu diário e as recordações apresentadas no livro Como e porque sou e não sou sociólogo (1968) revelam como se sentia seduzido pelo esteticismo e pelo naturalismo dos Goncourt.

Edmond e Jules Goncourt ${ }^{16}$ situam-se estética e historicamente entre o realismo de Flaubert e o naturalismo de Zola. Autores de romances históricos que destacam os traços negativos, o vício e a degenerescência moral da sociedade francesa do século XIX. Os Goncourt preocupavam-se marcantemente com o caráter documental de suas obras, por isso, pesquisavam uma ampla variedade de fontes, tais como jornais, novelas e pinturas. Aplicaram o método documental à redação de romances, segundo a técnica naturalista, que consiste na documentação objetiva e estudos científicos para a descrição dos estados patológicos sociais. Pretendiam a criação de uma linguagem especial, que se manifestasse de forma científica e altamente artística. Uma linguagem que pudesse exprimir a psicologia de seus personagens, e levasse os leitores a refletir sobre os ambientes retratados, com plasticidade e vivacidade. Escritores visuais, pictóricos e plásticos, tinham um meticuloso fascínio pela apresentação da realidade a partir de uma infinidade de minúcias extraídas do comportamento humano. Com o capricho dos miniaturistas e afiada percepção recolhiam estas minúcias da realidade humana viva e concreta.

Freyre estava em Paris, em 1922, quando registrou sua identificação com os Goncourt, escritores "fraternamente" próximos nas preferências, substâncias e formas parisienses de vida e de paisagem, "juntando ao gosto da cor o da precisão, agudeza e até pureza do traço, mesmo quando este vinha a ser intensificado [...] para dar relevo a alguma coisa de específico na sugestão ou na evocação ou na expressão de uma paisagem ou de um ambiente". Freyre admirava a estética, a plasticidade e a análise

\footnotetext{
${ }^{16}$ Edmond Huot de Goncourt (1822-1896) e Jules Huot de Goncourt (1830-1870) - Escritores franceses adeptos do naturalismo.
} 
minuciosa do comportamento humano e da intimidade presentes na literatura dos irmãos Goncourt, "os admiráveis pioneiros modernos de l'histoire intime... ce roman vrai". ${ }^{17}$

Em 1924, Freyre realizava pesquisas na Biblioteca Pública do Recife, quando encontrou um livro dos Goncourt que não conhecia: "livro delicioso". Freyre não revelou o nome da obra, mas registrou: "Não há na literatura francesa do século XIX obra mais interessante que dos Goncourt: única pelo que junta de inteligência à sensibilidade". E concluiu: "Ao lado dos Goncourt, os Zola e os Bourget se amesquinham em subescritores: pouco mais do que simples Ohnets..."18

Em 1925, Freyre manifestou mais uma vez a preocupação com seu estilo: "Que escritor pode haver sem forma? Sem plástica? Sem ritmo?'. Esta preocupação reforçou sua convicção de que o passado social de um povo só pode ser revelado em sua plasticidade pelo esforço de ressurreição da intimidade e do cotidiano social. Freyre reafirmou a importância de seus primeiros esforços teóricos e metodológicos na elaboração de sua tese de mestrado sobre a Social life in Brazil in the middle of the 19th century $^{19}$ (1922) e na organização do Livro do Nordeste (1925). Esforços de "ressurreição de um passado brasileiro mais íntimo ("l'histoire intime... roman vrai", como dizem os Goncourt) até esse passado tornar-se carne. Vida. Superação de tempo". ${ }^{20}$

A admiração de Gilberto Freyre pelo escritor Walter Pater ${ }^{21}$ começou aos dezoito anos com o curso sobre o ensaísmo inglês ${ }^{22}$ conduzido pelo Professor Armstrong, principalmente com a leitura da pequena obra-prima The child in the house, publicada originalmente na Macmillan's Magazine, em agosto de 1878. Freyre encontrou em W.Pater atributos que valorizava em um escritor admirável: a discussão de questões estéticas e de estilo; uma literatura que capturasse a experiência humana na sua fluidez e complexidade; a relevância da imaginação e a defesa da liberdade criativa do escritor.

Para W. Pater, as formas de escrever não são meros acidentes literários que dependem da escolha pessoal ou do capricho do autor. Dependem do assunto e das

\footnotetext{
${ }^{17}$ Freyre, Gilberto (1975). Tempo morto e outros tempos: trechos de um diário de adolescência e primeira mocidade, 1915-1930, Rio de Janeiro: J. Olympio, p.121.

${ }^{18}$ Ibidem, p.146.

${ }^{19}$ No prefácio à edição inglesa de sua tese de mestrado Freyre declarou que seu estudo sobre o Brasil dos meados do século XIX inspirou-se na caracterização da história íntima segundo os Goncourt: "l'histoire intime; c'est ce romam vrai que la posterité appelera peut-être l'histoire humaine". Inspiração de suas leituras de adolescente "daqueles dois escritores - escritores e historiadores - franceses: os irmãos Goncourt".

${ }^{20}$ Freyre, G. (1975). Op. Cit., p.177.

${ }^{21}$ Walter Horatio Pater (1839-1894) - Escritor e crítico inglês requintado. Pensador erudito. Seus princípios estéticos foram desenvolvidos por Oscar Wilde e George Moore.

${ }_{22}$ Durante seus estudos de graduação na Universidade de Baylor, no Texas (EUA).
} 
maneiras como a mente humana se relaciona com a verdade. $O$ ensaio não apresenta as inferências de forma sistematicamente organizadas, mas inferências e ligações que surgem por "associações mais ou menos livres e que se coadunam perfeitamente com a dubiedade e o inacabamento da experiência fugidia e da inevitável subjetividade de sua percepção". Pater considerou o ensaio como um método que se aproxima da realidade pela irregularidade, o fortuito, o ardor e a confusão da própria vida.

$\mathrm{Na}$ obra The child in the house (1878), Pater narra o reencontro de Florian Deleal com seu passado. Passado que se revelou pela busca de pequenos acidentes da infância que determinaram sua formação como homem. No conto, Florian ajuda um pobre velho, muito cansado, a carregar sua carga por uma distância. Durante o percurso ouve do velhinho sua história e descobre que eram da mesma região. Na noite do mesmo dia, Florian foi recompensado por seu compadecimento, e tem um sonho grandioso que descortina com grande clareza seu passado infantil: o lugar onde nascera e especialmente a casa onde cresceu. As portas, janelas, lareiras, os jardins e o perfume das flores da velha casa - detalhes da infância - relembrados no sonho fizeram com que Florian tomasse a decisão de recuperar sua história, sua formação, que Pater considerou como o processo de construção mental pelo qual somos o que somos. Florian recordou da casa onde vivera na infância e reencontrou em suas lembranças a criança movendo-se entre as paredes de lambris antigos, subindo as escadarias, vagando pelo grande sótão. Pequenos acontecimentos. Lembranças da paisagem infantil. Influências marcantes na formação de seus sentimentos, identificações, desejos, medos, aversões etc.

A experiência de Florian cativou a atenção de Freyre. Em 1923, o jovem intelectual registrou em seu diário que um dos seus maiores desejos era rever o São Severino dos Ramos: o Engenho de Pau d'Alho, no interior de Pernambuco. Freyre sentia muita saudade de sua meninice, da velha casa-grande e do engenho onde brincou menino, dos irmãos, primos e amigos de infância. Saudade da família, dos parentes, dos amigos e de seu amado Recife.

No prefácio à edição inglesa de sua tese de mestrado Social life in Brazil in the middle of the 19th century (1922), revisada em 1963, Freyre afirmou que este ensaio representava a tentativa de conhecer o Brasil "em sua vida quanto possível íntima", e lembrou: "ou - para usar das palavras de Walter Pater, quando Ihe perguntaram por que estudava história - 'para saber como vivia o povo, que trajos usava, que aparência tinha'. 
Principalmente para isto: para saber como viviam... os avós e bisavós de um brasileiro de hoje". 23

O jovem Freyre também admirava o estilo de Marcel Proust ${ }^{24}$, pois encontrou em sua obra, o mesmo sentido de l'histoire intime... ce roman vrai, dos Goncourt. M.Proust descreveu o universo do personagem, deformado e refletido segundo sua psicologia. Também considerou que o tempo só pode ser recuperado através da memória e só adquire eternidade com a obra de arte. Segundo os críticos, a principal contribuição da obra de Proust reside no desenvolvimento psicológico de seus personagens e na preocupação filosófica com o tempo.

Em sua obra-prima À la recherche du temps perdu (1913-1927), Proust revela as características fundamentais de seu estilo literário. Proust traçou a trajetória de seu herói desde a infância feliz até o compromisso romântico de sua própria consciência como escritor, e explicou corajosamente os abismos da psiché, as motivações inconscientes e a conduta irracional. Proust interpretava o tempo como elemento positivo e destrutivo, que só pode ser apreendido pela memória intuitiva. Sua percepção da seqüência temporal resultou de sua admiração pelas teorias do filósofo francês Henri Bérgson, que compreendia o tempo como um fluir constante: o passado e o presente como a mesma realidade. Seu estilo literário influenciou muitos escritores no século XX.

Proust buscava verdades eternas capazes de revelar a relação de sentido, a experiência e a memória esquecida. Assim, a memória pode ser estudada através da investigação minuciosa dos acontecimentos do cotidiano, do vivido, do poético. A beleza da vida é obscurecida pelos hábitos e pela rotina, mas essa beleza pode ser revelada pela arte.

Aparentemente os traços fundamentais do estilo literário de Proust seduziram o jovem Freyre: a introspecção meticulosa e emocionada do passado, o retrato psicológico dos personagens e a apropriação de diversos gêneros para a construção da narrativa. Também registrou em seu diário o apreço que tinha pelo Proust das análises líricas e clínicas, poéticas e científicas: um escritor-historiador ideal capaz de revelar o que há de mais íntimo no passado de um povo. Freyre manifestou seu interesse particular pelo primeiro livro da obra À la recherche du tempo perdu: o Du côté de Chez Swann como evocação do "tempo de menino".

\footnotetext{
${ }^{23}$ Freyre, Gilberto (1977). "Prefácio". In Vida social no Brasil em meados do século XIX, Rio de Janeiro: Artenova; Recife: Instituto Joaquim Nabuco de Pesquisas Sociais.

${ }^{24}$ Marcel Proust (1871-1922).
} 
Desde 1922, Freyre procurava aplicar a ideia de l'histoire intime dos Goncourt na análise histórica-social da vida de menino no Brasil. Estava interessado na "evocação e revelação da vida de menino" nos séculos coloniais, século XIX e começo do século XX, e em várias regiões brasileiras: engenho, fazenda, cidade, Rio, Recife, Bahia etc. Em 1924, reconheceu que havia chegado a sua fase intensa de proustianização. Em 1926, registrou em seu diário que desdenhava o que havia de ficção na literatura de Proust. Estava interessado no que o escritor francês poderia revelar-lhe sobre a história, a realidade e a histoire intime, bem como nas reflexões sobre assuntos relacionados à arte-ciência de evocação histórica e de revelação biográfica. Freyre buscava a fluidez que permite ver ou entrever a realidade: a fluidez proustiana. ${ }^{25}$

Aparentemente a influência de Proust revelou-lhe a chave teórica necessária para a pesquisa da história da vida de menino no Brasil: seu grande projeto intelectual para os próximos anos. Aprendeu que a história íntima pode ser revelada de forma plástica e vívida pela introspecção meticulosa e emocionada do passado. Podemos conjecturar que a busca do tempo perdido de Proust desdobrou-se em Freyre como a busca do menino perdido. As experiências registradas em seu diário demonstram que essa busca já havia começado antes da leitura do eminente escritor francês. Um interesse manifestado anteriormente em seu apreço pela literatura de Walter Pater e dos irmãos Goncourt, e que se alargou posteriormente pelo contato mais aprofundado com a obra de Marcel Proust.

Como vemos, o apreço de Gilberto Freyre pela literatura influenciou sobremaneira sua sensibilidade poética. $O$ jovem intelectual pernambucano identificou-se com escritores preciosos em sua busca introspectiva de um passado sensível e vívido. Assim, em Walter Pater reencontrou as lembranças da paisagem infantil no conto $A$ criança na casa; com os irmãos Goncourt aprendeu que podemos ressuscitar a intimidade e o cotidiano social, e que "A história íntima... um romance será"; com Marcel Proust, a introspecção meticulosa e emocionada do passado consubstanciou-se como a busca do menino perdido. Ademais, esses escritores realizaram algo muito valioso: a escrita acerca do passado, ficcional e romântica, está sempre marcada por uma representação poética do tempo e do espaço. Mas para Freyre, não importa que essa representação seja ficcional, pois sua

\footnotetext{
25 "Para Proust, é o artista-cientista que dá a certas coisas dentre as que ele vê ou evoca, "existência própria", uma espécie de "alma" que elas depois conservam em movimento como que próprio, desde que não há passado fixo. O próprio historiador que evoca o põe em movimento, sendo um homem fluido por sua atualidade em combinação com sua memória. Através dessa fluidez é que a realidade se deixa ver ou entrever; e nunca em sólidos perfeitamente fixos no tempo ou mesmo no espaço." Freyre, G. (1975). Op. Cit., p. 184.
} 
preocupação consistia apenas em absorver dessa literatura atributos valiosos como a fluidez, o estilo e a estética. Nesse ponto, podemos identificar em sua perspectiva, a mesma preocupação de Bergson sobre a centralidade da imagem para o estudo da memória e da percepção, bem como sua influência na "memória romanesca" de Proust, como demonstrou Le Goff.

Em 1919, Freyre estava na Universidade de Baylor/Texas quando tornou-se sóciocorrespondente do Diário de Pernambuco, onde escrevia artigos sobre temas sociais, culturais, políticos e regionais. ${ }^{26}$ Freyre preocupava-se com os embates intelectuais no Brasil, e com os desafios de construção da identidade nacional, por isso, manteve-se atualizado a respeito do pensamento social brasileiro presente nas obras de autores como Euclides da Cunha, Nina Rodrigues, Sylvio Romero, Manoel Bonfim, Oliveira Viana, Graça Aranha, Capistrano de Abreu, Lima Barreto, Licínio Cardoso, Monteiro Lobato, Tristão Ataíde, Mário de Andrade, Alberto Torres, entre outros.

Freyre concluiu seus estudos de pós-graduação na Universidade de Columbia/New York em 1922, onde defendeu sua tese de mestrado (Social life in Brazil in the middle of the 19th century). A primeira grande produção científico-acadêmica de um jovem pensador declaradamente identificado com a visão positiva do passado, e que desejava participar ativamente do projeto político-intelectual de construção da identidade nacional. Freyre escreveu que seu objetivo fundamental neste ensaio era conhecer o Brasil do século XIX. Desejava experimentar a "alegria" de "compreender" uma ordem social já desfeita, embora "ainda influente" sobre o "ethos brasileiro" ou simplesmente "compreender" o passado da sua própria gente, revelando o desafio de "lutar contra os preconceitos e as prevenções dos relatos convencionalmente históricos, tantos deles desprovidos de senso crítico".

Freyre lançou mão da obra de historiadores-sociólogos "magistrais" e "notáveis" como Joaquim Nabuco, Capistrano de Abreu e Oliveira Lima. Também utilizou fontes inovadoras para a época como daguerreótipos, litogravuras, livros de viagem, diários, jornais e revistas - material pesquisado, em grande parte, na Biblioteca HispanoAmericana de Oliveira Lima, na Universidade Católica de Washington D.C., na Biblioteca Pública de Nova York e na Biblioteca do Congresso dos Estados Unidos. Recolheu fatos recordados por remanescentes da "velha ordem", entre os quais a Senhora Richard

\footnotetext{
${ }^{26}$ Ver: Albuquerque Jr., Durval Muniz de (1999). A invenção do Nordeste e outras artes, Recife: FJN, Ed. Massangana; São Paulo: Cortez.
} 
Rundle, de Nova York, que viveu no Rio de Janeiro no século XIX, saudosa do Brasil de Pedro II, e o Dr. João Vicente Costa, velho brasileiro de Pernambuco com quem muito conversou na meninice.

Desta feita, enfrentou o desafio de juntar a sensibilidade de um estudo acerca do passado brasileiro à formação rigorosamente científica obtida em universidades estrangeiras. Descreveu a vida social no Brasil do século XIX observando critérios fundamentais como o estudo da l'histoire intime e a pesquisa detalhada e minuciosa do cotidiano. Realizou um estudo "menos político do que social" e valorizou aspectos "menos evidentes" ${ }^{27}$ da história social brasileira. O Brasil deste período era constituído de vários "Brasis" regionalmente diversos em relação as suas particularidades geográficas, históricas, culturais, políticas e econômicas.

$\mathrm{Na}$ sociedade brasileira agrária, patriarcal e escravocrata acentuava-se o antagonismo entre senhores de engenho e escravos. Mas Freyre destacou os aspectos menores como os relatos de viajantes sobre o acentuado processo de miscigenação; os anúncios de jornais sobre venda e fuga de escravos; o aspecto rústico do sertanejo (a enorme cabeleira, as calças de couro e a camisa de algodão); as indústrias caseiras de vinhos de jenipapo, charque, queijo de coalho, doces e bolos; as danças africanas e os ritmos sensuais do batuque dos escravos, que cantavam e tocavam marimba, nos dias de feriados - costume de alguns engenhos e fazendas; as atividades caseiras das donas-decasa ou sinhás-donas nas casas-grandes rurais e nos sobrados urbanos no cuidado com a alimentação, as roupas, as compras, a higiene etc.; o abuso sexual das escravas pelos senhores e seus filhos, que satisfaziam todos os seus gostos sexuais experimentando das pretas retintas às mulatas claras; as ruas e largos do Rio de Janeiro e Recife cheios de grupos de homens, conversando, fumando, tomando rapé, enquanto carregadores de café ou açúcar corriam com suas cargas, nus da cintura para cima, pele luzidia, dorsos oleosos de suor; a rua, a praça, o largo da matriz, a porta da botica - lugares de encontros dos homens da época.

Famílias aristocráticas ostentavam majestosas casas-grandes de engenho e sobrados urbanos com salas de visitas, muitos quartos de dormir e a grande sala de jantar; móveis de madeira pesada e nobre: mesas, sofás, cadeiras, marquises, camas; os

\footnotetext{
${ }^{27}$ Desprezou aspectos maiores como as finanças públicas, o progresso material, a produção do açúcar, a participação decisiva da religião na vida social, a corrupção do clero, o desprezo imperial das noções de higiene pública, o apego às tradições, a falta de apurado gosto literário e a preferência pela retórica, a quase total ausência de pensamento crítico entre as elites intelectuais, entre outros.
} 
enfeites de fitas de cor nos sofás e cadeiras; a presença majestosa do piano; e suas carruagens nobres. $\mathrm{Na}$ intimidade da casa-grande famílias numerosas recebiam amigos para jantar; a sonata ou polca era tocada pela senhora; jogos de salão como pilha-três; os poemas recitados pelos rapazes acompanhados ao piano; em algumas ocasiões o dono da casa virtuoso da flauta ou do violino, regalava as visitas com sua arte; jantar com grandes pratos de gorda carne de porco com feijão preto, de pirão, de canjica, de pães doces, de doces, de bolos e sobremesas frias de frutas nativas, muitas vezes preparadas e servidas pela própria sinhá-dona; as capelas e as orações domésticas; o respeito dos filhos aos pais.

Assim, o jovem Freyre realizou um "estudo indiciário" da vida social no Brasil do século XIX, a partir da análise minuciosa da intimidade e do cotidiano. O passado reconquistado pelo acesso à memória, como se cada "detalhe" constituísse uma peça peculiar de um quebra-cabeça histórico intrigante ou como se cada "pormenor" representasse uma pista reveladora de um enigma social apaixonante. ${ }^{28}$

Em 1925, Carlos Lyra Filho convidou Gilberto Freyre, que estava com apenas 25 anos, mas já era conhecido nos meios artísticos e intelectuais, para organizar um livro comemorativo do centenário do Diário de Pernambuco. Freyre imprimiu sua marca regionalista e indiciária na organização desta obra, pois deixou de lado o enaltecimento dos grandes acontecimentos como a colonização Duartina, a vitória sobre os flamengos ou as revoluções libertárias. Assim, encarregou alguns intelectuais, escritores e artistas regionais para apresentação de estudos sobre os cem anos de vida no Nordeste, mas de uma perspectiva micro-histórica, destacando a vida estudantil, os costumes, as tradições, a mulher, as festas, a música, a arte, o teatro, a literatura, a escravidão, ou seja, as particularidades históricas e culturais do Nordeste.

Desta feita, Oliveira Lima, Fidelino de Figueiredo e Francis Butler Simkins escreveram artigos sobre o açúcar; Aníbal Fernandes escreveu um ensaio sobre os problemas da capital pernambucana; a vida estudantil no Recife foi contada por Odilon Nestor; o poeta Manuel Bandeira escreveu Evocação do Recife, e recordou os hábitos e costumes que presenciou quando criança na casa do avô, na Rua da União, e as lembranças felizes dos banhos no rio Capibaribe; alguns especialistas escreveram sobre a economia de Pernambuco: a agricultura e a pecuária por Samuel Hardmenn, a indústria

\footnotetext{
${ }^{28}$ Defendi esta tese em minha dissertação de mestrado (Gilberto Freyre: indiciarismo, emoção e política na casa-grande e na senzala), apresentada ao Programa de Pós-graduação em História Social das Relações Políticas da Universidade Federal do Espírito Santo, em 2007.
} 
e o comércio por Gaspar Perez, a viação férrea por Graciliano Mendes; Luis Cedro escreveu um ensaio sobre D.Vital, bispo que enfrentou o poder imperial e a maçonaria; Joaquim Cardoso escreveu uma análise da poesia de Manuel Bandeira; Henrique Castriciano apresentou o perfil da poetisa norte-rio-grandense Nysia Floresta, que defendia ardorosamente posições feministas avançadas no século XIX; os temas antropológicos foram apresentados em suas particularidades locais: Júlio Belo escreveu sobre festas de engenho; Eloi de Souza realizou um estudo detalhado sobre os cantores do Nordeste; Leite Oiticica escreveu sobre a arte da confecção de rendas; Euclides Fonseca apresentou um ensaio sobre a vida musical no Nordeste; o teatro foi discutido por Samuel Campelo; a literatura foi objeto de estudo de França Pereira; o Movimento Abolicionista foi tema do paraibano Coriolano de Medeiros; o jornalismo por Manoel Caetano; Mário Belo escreveu sobre o Diário de Pernambuco e seu fundador Antônio José de Miranda Falcão; o drama das secas foi apresentado pelo cearense Tomás Pompeu Sobrinho.

O Livro do Nordeste tornou-se um dos principais documentos publicados sobre a vida nordestina, e apresentou uma rica profusão de estudos de historiadores, cientistas sociais, escritores, biógrafos, memorialistas, artistas e jornalistas.

Em 1926, Freyre viajou ao Rio de Janeiro para realizar pesquisas históricas sobre o período colonial brasileiro e registrou em seu diário sua decepção pela descaracterização arquitetônica e urbana da capital federal, que classificou como "mau gosto", "arrivismo", "rastaquerismo", "caricaturas ruins" em nome do progresso e do moderno. E escreveu indignado: "E certos modernistas a acharem isto bonito, progressista, moderno e a se regozijarem com a destruição das velharias. São uns cretinos, esses modernistas". ${ }^{29}$ Neste contexto, podemos afirmar que sua indignação é mais um sintoma da nostalgia e do conservadorismo romântico que sempre cultivou. Este comportamento não deve ser confundido com a negação insana do presente e do futuro, mas como uma tentativa desesperada de salvaguardar os vestígios do passado pela preservação dos monumentos históricos e de reconquistar a memória de sua infância pela introspecção proustiana: poética, científica e artística.

\footnotetext{
${ }^{29}$ Freyre, G. (1975). Op. Cit., p. 183.
} 


\section{Considerações finais}

O empenho de Freyre na recuperação e na revelação de um passado sensível está orientado por um perspectivismo histórico-sociológico que reconhece a dimensão afetiva da memória, o que aproxima sua leitura particular da ideia de "comunidade afetiva" de Halbwachs.

Sua descrição densa dos elementos estéticos, simbólicos e dos signos de nossa memória coletiva constitui um verdadeiro arsenal de "lugares de memória" (Nora) do passado brasileiro. Ademais, podemos inferir que a importância que atribuiu aos elementos menores, desprezados pela história política e econômica (a mulher, o artesanato, as poesias, a música, por exemplo) demonstra sua preocupação com a recuperação de "memórias silenciadas" (Pollak). Por fim, é notória a importância que atribuiu ao estudo das "representações coletivas" (Chartier), acentuando a complementaridade entre aspectos simbólicos, econômicos e políticos. Mas toda a narrativa freyreana é marcada por descontinuidades da memória, pois nada é linear e acabado em seu pensamento. Para o jovem Freyre, a obra - literária, artística ou científica - cria a realidade. Em sua escrita ocorre uma simbiose constante entre o leitor e a obra. Somos tomados por um incrível sentimento de realidade.

\section{Referências}

Albuquerque JR, Durval Muniz de (1999). A invenção do Nordeste e outras artes, Recife: FJN, Ed. Massangana; São Paulo: Cortez.

Bachelard, Gaston (2004). Ensaio sobre o conhecimento aproximado, Rio de Janeiro: Contraponto.

Chartier, Roger (1990). A história cultural: entre práticas e representações, Rio de Janeiro/Lisboa: Bernard Brasil/Difel.

Coelho, Claudio M. (2007). Gilberto Freyre: indiciarismo, emoção e política na casagrande e na senzala. Dissertação (Mestrado em História) - Programa de Pós-graduação em História Social das Relações Políticas, Universidade Federal do Espírito Santo, Vitória.

Freyre, Gilberto (1968). Como e porque sou e não sou sociólogo, Brasília: Ed. UNB.

(1975). Tempo morto e outros tempos: trechos de um diário de adolescência e primeira mocidade, 1915-1930, Rio de Janeiro: J. Olympio. 
(1977). Vida social no Brasil em meados do século XIX, Rio de Janeiro: Artenova; Recife: Instituto Joaquim Nabuco de Pesquisas Sociais.

Gadamer, Hans-Georg (2002). Verdade e método II, Petrópolis, RJ: Vozes.

Ginzburg, Carlo (1989). Mitos, emblemas, sinais: morfologia e história, São Paulo: Cia das letras.

Le Goff, Jacques (1990). História e memória, Campinas: Ed. UNICAMP.

Morin, Edgar (2005). O método 3: o conhecimento do conhecimento, Porto Alegre: Sulina.

Nora, Pierre (1993). "Entre memória e história: a problemática dos lugares". In Projeto História, n.10, p.7-28.

Pollak, Michael (1989). "Memória, esquecimento, silêncio". In Estudos Históricos, v.2, n.3, p.3-15.

Santos, Afonso C.M. dos (1998). Memória e história das ciências. Transcrição da palestra apresentada no MAST COLLOQUIA, em 05 de maio, Rio de Janeiro.

Recebido para publicação em novembro de 2012.

Aprovado para publicação em fevereiro de 2013. 